\title{
Communication skills training in obstetrics and gynaecology: whom should we train? A randomized controlled trial
}

\author{
Judith Alder • Regula Christen • Elisabeth Zemp • \\ Johannes Bitzer
}

Received: 5 March 2007 / Accepted: 29 May 2007 / Published online: 19 June 2007

(C) Springer-Verlag 2007

\begin{abstract}
Objective To determine whether patient-physician communication in obstetrics and gynaecology can be improved by a training program and to investigate if physicians with poorer performance before the training show greater improvement in communication skills scores over the course of the study.

Design Intervention study with randomisation in training $(n=16)$ and control group $(n=16)$ and patient satisfaction and communication skills of physicians as outcome variables. Physicians' communication skills were assessed by independent raters using a standardised evaluation instrument (adapted version of the MAAS-R) to analyse video recorded interviews before and after the training. Patient satisfaction was assessed with a patient satisfaction questionnaire.

Results Using general linear model (GLM) for repeated measures no group $\times$ time interaction nor time effects were found for physicians' communication skills. No group $\times$ time interaction was found for patients' satisfaction scores; however the significant time effect was mostly attributable to positive changes in patients' rating of the training group. Physicians with poorer performance at the beginning showed greater improvements over the course of the study, especially in the training group.
\end{abstract}

J. Alder $(\bowtie) \cdot$ J. Bitzer

University Women's Hospital Basel,

Spitalstrasse 21, 4031 Basel, Switzerland

e-mail: jalder@uhbs.ch

\section{R. Christen}

Department of Psychology, Psychiatric University Clinics,

Wilhelm-Klein Strasse 27, 4054 Basel, Switzerland

E. Zemp

Institute for Social- and Preventive Medicine,

Steinengraben 49, 4051 Basel, Switzerland
Conclusions In this randomized controlled trial marginal intervention effects for the improvement of communication skills and only partial changes in patient satisfaction scores from pre to post training were shown. However, physicians with poorer performance at the beginning showed greater improvements, suggesting that competence levels were already relatively high at the beginning of the study. Also, formation of communication training groups should be based on specific skill deficits rather than being implemented unspecifically for an entire team of physicians.

Keywords Communication training .

Patient satisfaction - Obstetrics and gynaecology ·

Patient centred communication

\section{Introduction}

Patient-physician communication in general encompasses a wide range of interactions, whose quality and content have been shown to have important effects on both participants. "Good" communication with patients has been associated in studies of general practitioners and internists with improved patient adherence, lowered risk of malpractice litigation, improved health outcomes (emotional health, symptom resolution, function, physiologic measures and pain control) [1-5]. Quantifying and measuring communication skills has therefore become an important instrument of quality development in different services especially in general and internal medicine and teaching communication skills has become an important part of medical students training in many countries [6-9]. The patient-gynaecologist communication is characterised by several specific features placing great demand on the communication behaviour of the physician: the health problems presented 
are frequently of intimate nature and have a high emotional impact. Diagnostic and therapeutic interventions influence body image, sexuality and self esteem. Gynaecologists have to respond to these emotions and personal beliefs and values of their patients [10].

Reproduction and sexuality are issues that encompass the patient's whole life, involving specific life cycles and psychosocial issues. Gynaecologists have to be able to take a psychosocial, biographical and systemic perspective to understand their patients [11].

Many healthy women consult with concerns regarding health maintenance, promotion and health behaviour. They are not patients in a traditional sense but partners with an interest in informed decision-making, autonomy and enhancement of their health related interests and objectives. Gynaecologists need therefore a specific competence in patient education, information exchange, behavioural change and negotiation.

These high demands are in rather sharp contrast to the limited studies on the quality of communication in obstetrical and gynaecological services and the effect on patient's satisfaction $[12,13]$. Furthermore the specific communicative demands in women's health care have not yet been clearly defined and operationalised and there is a lack of training programs that take into consideration the needs of this speciality as described above [14]. Reasons for this discrepancy can be manifold. The daily work load in obstetrics and gynaecology does not permit to develop a special focus on communication, because the priority lies on medical or surgical interventions. Obstetrics and gynaecology being traditionally a surgical speciality has been less focused on psychosocial approaches. Communication skills are difficult to quantify and evaluate and it is therefore difficult to obtain scientific evidence about possible effects.

We have therefore developed a research program to study the possibility to implement a brief communication skills training program for staff members of a department of obstetrics and gynaecology, which can be integrated into the daily work schedule. The effects of the communication training on physicians' communication skills and its effect on patient satisfaction were investigated. In addition, it was investigated if physicians with poorer performance before the intervention would benefit more from the training. The study addressed these questions by means of a controlled randomised intervention.

\section{Methods}

\section{Design}

The study was designed as a randomised intervention study. As outcome variables, communication skills and patient satisfaction were assessed before and after the training by the analysis of videotaped medical consultations and by questionnaire. The study has been approved by the Ethical Committee of Basel

\section{Sample}

\section{Physicians}

Power analysis was computed to assess the required sample size of physicians in order to detect pre- and post intervention differences $(\alpha$-level of $5 \%$, level of power $80 \%)$ in patient satisfaction and in a change of communication skills scores. Based on the results reported by Kravitz et al. [15], the required group-size to detect an intervention-effect in the patients' satisfaction scores, the required sample size in each group was $n=16$. To detect a given interventioneffect on the MAAS-R sub-scores, sample size was calculated on the basis of the results reported by Langewitz et al. [16], and was estimated to be between $n=5$ and $n=17$ for the different subscores. Therefore, we planned a total of 32 physicians to participate in the training and control group.

All physicians of the department of obstetrics and gynaecology of the University Women's Hospital of Basel, Switzerland were recruited for the study with the exception of the head of department and one of the authors (JB) who participated as a trainer. Participants were randomised to training group $(n=18)$ and control group $(n=18)$ stratified for position and gender. Over the course of the study, seven physicians ( 3 training group, 4 control group) left the department due to job reasons. Considering the time plan of the study, it was possible to enter the first three new colleagues in the study, two of them randomised to control and one to training condition. However, this resulted in changes in the composition of the study groups: The final training group $(n=16)$ consisted of $56.25 \%$ of residents and $43.75 \%$ staff members with a mean of years of experience of 6.9 years. The control group $(n=16)$ consisted of $50 \%$ of residents and $50 \%$ of staff members and their mean of years of experience was 4.6 years. Training and control group therefore did differ in years of professional experience $(T=2.7, P<0.05)$.

\section{Patients}

Interviews were recorded with real patients recruited from the outpatient department and with simulated patients. Real patients were asked for participation as they came for their regular appointment to the clinic. Twenty-two $(15.2 \%)$ of the videotapes were made with real patients before the intervention and $11(8.6 \%)$ were made with real patients after the intervention.

Simulated patients were trained in their patient roles by an external trained trainer. Patient scripts were derived 
from clinical examples described by an experienced clinician and one of the authors (JB).

Description of the intervention

\section{Teaching objectives}

Participants should learn to conceive and practice the consultation as a problem solving process with the following tasks:

- Practice patient centred communication

- Establish and maintain a therapeutic relationship

- Understand the problem of the patient from a biopsychosocial perspective

- Exchange information and educate patients

- Encourage shared decision making.

\section{Structure of the course}

The communication skills training was held by three of the authors. Training literature served as the basis of the development of the intervention while the content was adapted to the setting of obstetrics and gynaecology. The training program consisted of three different elements: workshops, practice seminars and progress assessment meetings. An initial one-day workshop aimed at giving the participants the theoretical background for the consultations and the communicative and interpersonal processes. The theoretical background of physician-patient communication, different communication models, general and specific communication skills were discussed and summarised in the training handout containing the relevant elements of the theoretical background and communication examples. Three half-day practice seminars were held for 4-5 participants where the acquired knowledge and specific communication skills were practised (with videofeedback). Role plays and modelling were used as additional teaching strategies. The last part of the intervention consisted of five to six $1 \mathrm{~h}$ supervision sessions for each participant (single setting and small groups) over a 3-month period. Trainees discussed problems related to types of communication they have encountered in their clinical work, and were supervised by the group and the trainer. Short communication sequences were practised.

\section{Data collection}

Communication skills were assessed before (T1) and after (T2) the training program for the training group while in the control group skills were assessed at $\mathrm{T} 1$ and $\mathrm{T} 2$ with no intervention. Each physician at $\mathrm{T} 1$ and $\mathrm{T} 2$ performed in four videotaped first medical encounters. The percentage of simulated patients was the same in both groups and there were no differences in communication skills and patient satisfaction scores in real and simulated patients.

Digital video cameras were installed in the consultation rooms and videotape sessions were supervised by one of the authors. Videotaping of real medical encounters was comparable to that of simulated patients. Physicians being videotaped with simulated patients received a prepared "patient file" before the consultation which contained the relevant patient data comparable to real patient files. Training and control group did not differ regarding length of the consultation.

After the consultation, patients were asked to fill out a satisfaction with the consultation questionnaire. Real and simulated patients were blinded as to whether the physician belonged to the intervention or the control group.

\section{Instruments}

\section{MAAS-R (the revised Maastricht history-taking and advice checklist)}

The MAAS-R [17] consists of different sections, where the occurrence or quality of certain behaviour is rated: entry, overall orientation, exploration of reasons for the encounter, structure of diagnostic plan, history taking (medical and psychosocial), evaluation and giving information, management plan, and evaluation of the consultation and general evaluation.

The instrument was chosen as an appropriate interview measure given that it is based on a model of medical interviewing and that it is reproducible in another cultural and institutional context and has satisfactory inter-rater reliability [18].

MAAS-R provides global scores (mean and SD) that rate specific behaviours or the quality of, e.g., data gathering. Sum scores result from checklists where the occurrence of certain behaviour or the mentioning of specific information is marked. The original structure of the instrument was slightly adapted for the speciality field of the study (obstetrics and gynaecology) clustering the original categories in the sections entry, history taking, mutual problem definition, information giving, shared decision making and feedback/termination of the consultation. For data analysis, single categories were summarized according to the teaching objectives (see Table 1).

In total, six independent raters (advanced psychology students), blinded for group affiliation were trained to evaluate videotapes of physician-patient interactions at $\mathrm{T} 1$ and T2. Kappa coefficient was calculated to determine the degree of agreement between two raters for nominal scaled items. The coefficient ranged from 0.57 (moderate agreement) to 1.0 (excellent agreement). Spearman Rho was calculated for the inter-rater agreement of ordinal and interval scaled items. The coefficient ranged from 0.69 to 0.94 which again can be classified as moderate to very good. 
Table 1 Communication categories from the adapted version of MAAS-R according to the teaching objectives

\begin{tabular}{|c|c|}
\hline Teaching objective & Included single items \\
\hline Practice patient centred communication & $\begin{array}{l}\text { - Open questions } \\
\text { - Addressing patients concerns } \\
\text { - Asking patient's reactions } \\
\text { - Repetitions } \\
\text { - Affirmations } \\
\text { - Adaptation of language } \\
\text { - Space for patients }\end{array}$ \\
\hline Establish and maintain a therapeutic relationship & $\begin{array}{l}\text { - Introduction } \\
\text { - Empathy } \\
\text { - Non verbal communication } \\
\text { - Emotion handling } \\
\text { - Aim of consultation } \\
\text { - Checking for satisfaction with consultation } \\
\text { - Checking for reaching aims of consultation }\end{array}$ \\
\hline $\begin{array}{l}\text { Understand the problem of the patient } \\
\text { from a biopsychosocial perspective }\end{array}$ & $\begin{array}{l}\text { - Assessment of complaints } \\
\text { - Course of complaints } \\
\text { - Family history } \\
\text { - System history } \\
\text { - Previous treatments } \\
\text { - Drug consumption } \\
\text { - Psychosocial history } \\
\text { - Influence of complaints of functioning } \\
\text { - Previous coping }\end{array}$ \\
\hline Exchange information and educate patients & $\begin{array}{l}\text { - Announcement of history taking } \\
\text { - Explanations of consultation process } \\
\text { - Checking back understanding } \\
\text { - Announcement of phases } \\
\text { - Conclusion of phases } \\
\text { - Information of findings } \\
\text { - Discussion of etiological factors } \\
\text { - Prognosis (duration, severity) }\end{array}$ \\
\hline Encourage shared decision making & $\begin{array}{l}\text { - Assessment of patient perspective } \\
\text { - Depiction of physician perspective } \\
\text { - Punctuation of conflicts } \\
\text { - Working through differences } \\
\text { - Common problem perspective } \\
\text { - Naming of treatment options } \\
\text { - Naming of disadvantages } \\
\text { - Suggestions of proceeding } \\
\text { - Agreement on how } \\
\text { - Agreement on where }\end{array}$ \\
\hline
\end{tabular}

\section{Patient satisfaction}

Patients' perspective of the consultation was assessed by using an adapted version of the Kravitz questionnaire focusing on satisfaction [15]. Questions regarding satisfaction with technical skills of the physician were ignored in the questionnaire which was used in the current study while three items were added addressing satisfaction with patient-physician relationship and five items additionally focusing at satisfaction with received information, thus resulting in a questionnaire of 13 items.

Questions were answered on a five-point Likert scale ranging from "does not apply at all" to "applies very much". The scale used in this study showed to have satisfactory reliability criteria with a Cronbach's Alpha of
0.93. For analysis of validity a factor analysis was conducted which provided three factors explaining $75 \%$ of the total variance (KMO-value .89): satisfaction with consultation and patient-doctor relationship (7 items), expected compliance ( 3 items) and patient understanding (3 items).

\section{Statistical analysis}

For each physician of the training and the control group, mean scores were calculated on the basis of the performance in the four videotaped consultation types. This resulted in one communication score per domain and physician at $\mathrm{T} 1$ and $\mathrm{T} 2$. In addition, mean patient satisfaction scores were calculated on the basis of the satisfaction ratings 
in each of the four medical encounters resulting in one patient satisfaction score per physician.

Means of satisfaction and communication skills scores were normally distributed. Pre- to post-training effects were analysed using a general linear model (GLM) for repeated measures with a two-folded factor group (training and control group) and a two-folded factor time (pre and post intervention) and innersubject contrasts were calculated to look for pre-post differences in communication and patient satisfaction scores.

In order to investigate if physicians with poorer performance at $\mathrm{T} 1$ will show higher improvement in communication skills, in a linear regression analysis communication skills scores at $\mathrm{T} 1$ served as predictors for $\mathrm{T} 2-\mathrm{T} 1$ communication score differences.

$P$ values were two-tailed and the level of statistical significance was 0.05 . Calculations were performed with the Statistical Package for Social Sciences (SPSS), version 13.

\section{Results}

Communication skills before and after the training

Table 2 presents mean values and standard deviations of the communication skills scores before and after the training of both groups by teaching objectives. $P$ levels for time (pre- to postintervention) $\times$ group (intervention and control group) interaction are shown in the last column reflecting no significant interactions in communicative scores. In addition, inner subject contrasts for the factor time and post-hoc $t$ tests for group comparison did not reflect any time or group differences in the dependent variables.

Patient satisfaction scores before and after the training

Table 3 shows satisfaction questionnaire sum scores for the factors satisfaction with consultation and doctor-patientrelationship, compliance and patient understanding as well as overall sum score.

In none of the satisfaction scores time $\times$ group interaction was significant, even though the factor time (pre- to post-intervention) for satisfaction with consultation and doctor-patient-relationship, $(F=9.33, P<0.01)$, compliance $(F=16.16, P<0.01)$ and patient understanding $(F=7.15, P<0.05)$ showed significant results. The pre- to post-test changes were mostly attributable to higher satisfaction scores in the training group at post-intervention (satisfaction with consultation and doctor-patient-relationship: $T-2.50, P<0.05$; compliance: $T=-3.40, P<0.01$; patient understanding: $T=-2.30, P<0.05$ ) and to a lesser degree to higher satisfaction scores in the control group at the second time point of assessment (compliance: $T-2.20$, $P<0.05)$.

Table 2 Mean values ( \pm standard deviations) of communication skills scores by teaching objective, group adherence, and time point of assessment

\begin{tabular}{|c|c|c|c|c|c|}
\hline \multirow[t]{2}{*}{ Teaching objective } & \multicolumn{2}{|c|}{ Training group $(n=16)$} & \multicolumn{2}{|c|}{ Control group $(n=16)$} & \multirow{2}{*}{$\begin{array}{l}\text { Time } \times \text { group } \\
P\end{array}$} \\
\hline & $\mathrm{T} 1$ & $\mathrm{~T} 2$ & $\mathrm{~T} 1$ & $\mathrm{~T} 2$ & \\
\hline Patient centred communication (range: $0-3.3$ ) & $2.37 \pm 0.40$ & $2.51 \pm 0.35$ & $2.27 \pm 0.31$ & $2.32 \pm 0.39$ & 0.57 \\
\hline Establish a therapeutic relationship (range: $0-3.1$ ) & $2.03 \pm 0.32$ & $2.14 \pm 0.28$ & $1.99 \pm 0.25$ & $2.09 \pm 0.27$ & 0.92 \\
\hline Understanding the problem (range: $0-2.3$ ) & $1.22 \pm 0.36$ & $1.17 \pm 0.28$ & $1.18 \pm 0.31$ & $1.25 \pm 0.37$ & 0.38 \\
\hline Give information and educate (range: $0-2$ & $0.65 \pm 0.19$ & $0.71 \pm 0.25$ & $0.57 \pm 0.20$ & $0.77 \pm 0.38$ & 0.20 \\
\hline Shared decision making (range: $0-2.3$ ) & $1.61 \pm 0.22$ & $1.74 \pm 0.24$ & $1.61 \pm 0.18$ & $1.71 \pm 0.37$ & 0.85 \\
\hline
\end{tabular}

${ }^{a}$ GLM for repeated measures

Table 3 Mean values ( \pm standard deviations) for patient satisfaction (factor scores and sum score) by group adherence and time point of assessment

\begin{tabular}{|c|c|c|c|c|c|}
\hline \multirow[t]{2}{*}{ Satisfaction factor } & \multicolumn{2}{|c|}{$\begin{array}{l}\text { Patients of training } \\
\text { group }(n=64)\end{array}$} & \multicolumn{2}{|c|}{$\begin{array}{l}\text { Patients of control } \\
\text { group }(n=64)\end{array}$} & \multirow{2}{*}{ 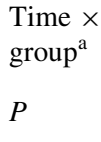 } \\
\hline & $\mathrm{T} 1$ & $\mathrm{~T} 2$ & $\mathrm{~T} 1$ & $\mathrm{~T} 2$ & \\
\hline Consultation and relationship (range: $0-4$ ) & $2.08 \pm 0.59$ & $2.38 \pm 0.31$ & $2.11 \pm 0.57$ & $2.23 \pm 0.42$ & 0.20 \\
\hline Compliance (range: $0-4$ ) & $2.01 \pm 0.55$ & $2.48 \pm 0.27$ & $2.03 \pm 0.51$ & $2.29 \pm 0.35$ & 0.24 \\
\hline Patient understanding (range: $0-4$ ) & $2.29 \pm 0.37$ & $2.54 \pm 0.23$ & $2.42 \pm 0.32$ & $2.54 \pm 0.30$ & 0.36 \\
\hline Sum score (range: $0-52$ ) & $27.62 \pm 7.41$ & $32.21 \pm 6.52$ & $28.18 \pm 7.33$ & $30.38 \pm 5.14$ & 0.12 \\
\hline
\end{tabular}

${ }^{a}$ GLM for repeated measures 
Prediction of improvement in communication skills by pre-intervention score levels

In a first step, mean scores of pre-to-post training differences in communication scores according to the teaching objectives were calculated for both groups to reflect changes in communication skills. In a second step, communication scores at $\mathrm{T} 1$ served as independent variables to predict pre-to-post training differences in communication scores in linear regression analysis.

Table 4 displays those variables where a lower performance at $\mathrm{T} 1$ was predictive for higher pre-post differences in communication skills scores.

In the training group, lower levels of performance were followed by higher skill improvements from $\mathrm{T} 1$ to $\mathrm{T} 2$ in all of the communication domains indicating that physicians with poorer performance tended to profit more from the training. In the control group poorer performance at T1 predicted higher improvements only in the domains establish therapeutic relationship, problem understanding and shared decision making, reflecting intervention independent learning processes in these categories. On the other hand, performances at $\mathrm{T} 1$ were not predictive for improvements in the domains patient centred communication and give information and educate the patient.

\section{Discussion}

Effectiveness of the intervention

In this randomised trial only an indirect effect of a communication skills training for gynaecologists was observed: while observer based ratings of communicative skills did not differ between training and control group from pre to post intervention, a greater increase in patient satisfaction scores was noted for the patients of the training group. Whether the implementation of the training program could have had an impact on the culture of the institution leading to model learning, seminal effects, and cross contamination among physicians $[19,20]$ can not be answered because we would have had to use a control group outside the institution which was not feasible.
The results are in line with the conclusions of the systematic review of Hulsman et al. [21], where studies with the most appropriate study designs (randomized, controlled), showed the least training effects. This can partly be due to the effect that in randomized controlled trials quality of pre-intervention communication skills in general is not a selection criterion, thereby leading to heterogeneous group compositions.

Improvement of communication skills related to baseline performance

Therefore, in a second step, we investigated if baseline communicative skills prior to the intervention are related to improvements over the course of the study period. The analysis suggests that physicians with poorer performance at baseline showed greater improvements over time and this was especially more pronounced for trainees compared to controls. This finding is inline with the observation of Gunn et al. [22], who found no improvements in communication skills in general practitioners with excellent performance prior to an intervention to detect postnatal problems. In our study, especially deficits in the domains patient centred communication and giving information and educate the patient were sensitive to training induced changes.

From these results, two basic principles for communication skills trainings can be suggested. First, prior to an intervention, baseline communication skills should be assessed leading to an individual profile of strengths and weaknesses. Second, interventions should focus at training specific skills more individually rather than being offered as a standardized package to a with regard to their communicative competence heterogeneous group of physicians.

Principles of communication skills trainings

So far, three central aspects for the planning and evaluation of training programs for communication skills have been described: Which aspects of patient-physician communication should be trained, how should they be trained, and how should training be evaluated [15, 16, 23-25]. In the literature, there is a considerable number of partially contradictory skills which are related to the quality of
Table 4 Linear regression analysis for lower performance at $\mathrm{T} 1$ predicting higher improvements in communication skills scores

\begin{tabular}{|c|c|c|c|c|c|c|}
\hline \multirow[t]{2}{*}{ Communication domain } & \multicolumn{3}{|c|}{ Training group } & \multicolumn{3}{|c|}{ Control group } \\
\hline & Beta & $T$ & $P$ & Beta & $T$ & $P$ \\
\hline Patient centred communication & -0.63 & -3.01 & $<0.01$ & -0.42 & -1.74 & $<0.2$ \\
\hline Establish a therapeutic relationship & -0.62 & -2.93 & $<0.02$ & -0.60 & -2.82 & $<0.02$ \\
\hline Understanding the problem & -0.69 & -3.55 & $<0.01$ & -0.52 & -2.27 & $<0.04$ \\
\hline Give information and educate patient & -0.55 & -2.45 & $<0.03$ & 0.02 & 0.08 & $<0.95$ \\
\hline Shared decision making & -0.66 & -3.27 & $<0.01$ & -0.56 & -2.51 & $<0.03$ \\
\hline
\end{tabular}


physician-patient communication [5, 26-28]. However, so far widely accepted guidelines for communication behaviour only exist for specific clinical situations such as breaking bad news [29, 30].

We chose for our training program teaching objectives which on the one hand represent the most frequently studied skills and on the other hand seemed to us specific for the needs of patients in obstetrics and gynaecology [31-33]. Communication skills training programs in medicine introduce various teaching techniques and use different didactic strategies [16, 34-37]. Besides the transmission of declarative knowledge, learning how to communicate is mostly acquired over procedural learning and only a few teaching strategies have so far been evaluated in their effectiveness for such learning processes [38]. For procedural knowledge acquisition the trainee optimally is actively involved in the training situation and is confronted step by step with more complex problems and techniques. It is central that the trainee learns when to intervene how [39].

With regard to the issue of evaluating the training program, a wide variety of instruments have been developed including questionnaires and rating instruments [18]. The appropriateness of the use of the MAAS-R in this study for the detection of training effects in the specialty of gynaecology and obstetrics has to be questioned. In OB/GYN a substantial amount of consultations focus on preventive care, health counselling, and non-disease related questions. Thus, the MAAS-R which looks in a large proportion on more technical rather than interpersonal skills might not have been the right measure to look for effects in our training program.

As another limitation of the study, employment fluctuations lead to group differences regarding years of professional experience. Also, even though power analysis expected a total sample size of $N=32$ to have sufficient power to detect group differences, further trials with larger sample sizes are needed. As one of the results of the present investigation, studies should focus more extensively on trainee selection prior to an intervention and provide more individualized communication skills training. Thus, training research should aim to answer the question of who should be trained by whom with what intervention to produce which effects.

Acknowledgments The study was kindly funded by the Swiss National Fund. The funding source had no involvement in the work presented here.

\section{References}

1. Stewart MA (1995) Effective physician-patient communication and health outcomes: a review. CMAJ 152(9):1423-1433

2. Levinson W, Roter DL, Mullooly JP, Dull VT, Frankel RM (1997) Physician-patient communication. The relationship with malprac- tice claims among primary care physicians and surgeons. JAMA 277(7):553-559

3. Levinson W, Chaumeton N (1999) Communication between surgeons and patients in routine office visits. Surgery 125(2):127-134

4. Bull SA, Hu XH, Hunkeler EM, Lee JY, Ming EE, Markson LE, Fireman B (2002) Discontinuation of use and switching of antidepressants: influence of patient-physician communication. JAMA 288(11):1403-1409

5. Mead N, Bower P, Hann M (2002) The impact of general practitioners' patient-centredness on patients' post-consultation satisfaction and enablement. Soc Sci Med 55(2):283-299

6. Kurtz SM (2002) Doctor-patient communication: principles and practices. Can J Neurol Sci 29(Suppl 2):S23-S29

7. Klass D, DeChamplain A, Fletscher E, King A, Macmillen M (1998) Development of a performance-based test of clinical skills for the United States medical license in examination. Fed Bull 85:177-185

8. Hargie O, Dickson D, Boohan M, Hughes K (1998) A survey of communication skills training in UK schools of medicine: present practices and prospective proposals. Med Educ 32(1):25-34

9. Cegala DJ, Lenzmeier Broz S (2002) Physician communication skills training: a review of theoretical backgrounds, objectives and skills. Med Educ 36(11):1004-1016

10. Bitzer J, Stauber M (1995) Psychosomatic obstetrics and gynecology. Monduzzi Editore Bologna

11. Fathalla M (1997) From obstetrics and gynecology to women's health. Parthenon, New York

12. van Dulmen AM (1999) Communication during gynecological outpatient encounters. J Psychosom Obstet Gynaecol 20(3):119-126

13. van Dulmen AM, Bensing JM (2000) Gender differences in gynecologist communication. Women Health 30(3):49-61

14. van Dulmen AM, van Weert JC (2001) Effects of gynaecological education on interpersonal communication skills. BJOG 108(5):485-491

15. Kravitz RL, Cope DW, Bhrany V, Leake B (1994) Internal medicine patients' expectations for care during office visits. J Gen Intern Med 9(2):75-81

16. Langewitz WA, Eich P, Kiss A, Wossmer B (1998) Improving communication skills - a randomized controlled behaviorally oriented intervention study for residents in internal medicine. Psychosom Med 60(3):268-276

17. van Thiel J, Kraan HF, Van Der Vleuten CP (1991) Reliability and feasibility of measuring medical interviewing skills: the revised Maastricht history-taking and advice checklist. Med Educ 25(3):224-229

18. Kraan H, Crijnen A, Van Der Vleuten CP, Imbos T (1995) Evaluation instruments for medical interviewing skills. In: Lipkin M, Putnam S, Lazare (Eds) The medical interview. Springer, New York

19. Branch WT Jr, Kern D, Haidet P, Weissmann P, Gracey CF, Mitchell G, Inui T (2001) The patient-physician relationship teaching the human dimensions of care in clinical settings. JAMA 286(9): 1067-1074

20. Hutchinson L (1999) Evaluating and researching the effectiveness of educational interventions. BMJ 318(7193):1267-1269

21. Hulsman RL, Ros WJ, Winnubst JA, Bensing JM (1999) Teaching clinically experienced physicians communication skills. A review of evaluation studies. Med Educ 33(9):655-668

22. Gunn J, Southern D, Chondros P, Thomson P, Robertson K (2003) Guidelines for assessing postnatal problems: introducing evidence-based guidelines in Australian general practice. Fam Pract 20(4):382-389

23. Makoul G (2001) The SEGUE framework for teaching and assessing communication skills. Patient Educ Couns 45(1):23-34

24. Makoul G (2001) Essential elements of communication in medical encounters: the Kalamazoo consensus statement. Acad Med 76(4):390-393 
25. Bensing J, van Dulmen S, Tates K (2003) Communication in context: new directions in communication research. Patient Educ Couns 50(1):27-32

26. Roter DL, Hall JA, Kern DE, Barker LR, Cole KA, Roca RP (1995) Improving physicians' interviewing skills and reducing patients' emotional distress. A randomized clinical trial. Arch Intern Med 155(17):1877-1884

27. McKinstry B (2000) Do patients wish to be involved in decision making in the consultation? A cross sectional survey with video vignettes. BMJ 321(7265):867-871

28. Little P, Everitt H, Williamson I, Warner G, Moore M, Gould C, Ferrier K, Payne S (2001) Preferences of patients for patient centred approach to consultation in primary care: observational study. BMJ 322(7284):468-472

29. Fallowfield L (1993) Giving sad and bad news. Lancet 341(8843):476-478

30. Girgis A, Sanson-Fisher RW (1998) Breaking bad news 1: current best advice for clinicians. Behav Med 24(2):53-59

31. Little P, Everitt H, Williamson I, Warner G, Moore M, Gould C, Ferrier K, Payne S (2001) Observational study of effect of patient centredness and positive approach on outcomes of general practice consultations. BMJ 323(7318):908-911

32. van Dulmen S, Nubling M, Langewitz W (2003) Doctor's responses to patients' concerns; an exploration of communication sequences in gynaecology. Epidemiol Psichiatr Soc 12(2):98-102
33. Mead N, Bower P (2002) Patient-centred consultations and outcomes in primary care: a review of the literature. Patient Educ Couns 48(1):51-61

34. Christensen JF, Levinson W, Colligan JL, Dunn PM, Jones SR, Morgenstern A (1987) A one-day communication workshop for internal medicine residents. J Med Educ 62(8):687-690

35. Edwards A, Tzelepis A, Klingbeil C, Melgar T, Speece M, Schubiner H, Burack R (1996) Fifteen years of a videotape review program for internal medicine and medicine-pediatrics residents. Acad Med 71(7):744-748

36. Farnill D, Todisco J, Hayes SC, Bartlett D (1997) Videotaped interviewing of non-English speakers: training for medical students with volunteer clients. Med Educ 31(2):87-93

37. Gordon JH, Walerstein SJ, Pollack S (1996) The advanced clinical skills program in medical interviewing: a block curriculum for residents in medicine. Int J Psychiatry Med 26(4):411-429

38. Binder J (1997) The mental functioning and training of psychodynamic psychotherapistst. Presentation at the Conference on the training of psychotherapists' information processing in 2000. Grindelwald

39. Silberschatz G, Fretter PB, Curtis JT (1986) How do interpretations influence the process of psychotherapy? J Consult Clin Psychol 54(5):646-652 